\title{
The broad-spectrum caspase inhibitor Boc-Asp-CMK induces cell death in human leukaemia cells
}

\author{
Ivo Frydrych ${ }^{\mathrm{a}, 1}$, Petr Mlejnek ${ }^{\mathrm{a}, 1, *}$, Petr Dolezel ${ }^{\mathrm{a}}$, Vassilis Zoumpourlis ${ }^{\mathrm{b}}$, Petra Krumpochova ${ }^{\mathrm{a}}$ \\ a Department of Biology, Faculty of Medicine, Palacky University, Hnevotinska 3, Olomouc 77515, Czech Republic \\ ${ }^{\mathrm{b}}$ Unit of Biomedical Applications, Institute of Biological Research and Biotechnology, National Hellenic Research Foundation, Athens, Greece
}

\section{A R T I C L E I N F O}

\section{Article history:}

Received 30 October 2007

Accepted 28 February 2008

Available online 4 March 2008

\section{Keywords:}

Caspase-3 processing

Cell respiration

Apoptosis

Necrosis

U937 cells

\begin{abstract}
A B S T R A C T
Synthetic caspase inhibitors and particularly broad-spectrum caspase inhibitors can prevent cells from death or at least slow down cell death process and abrogate some apoptotic hallmarks [Kitanaka, C., Kuchino, Y., 1999. Caspase-independent programmed cell death with necrotic morphology. Cell Death and Differentiation 6, 508-515]. However, not all synthetic caspase inhibitors diminish cell death. We have found that the broad-spectrum caspase inhibitor Boc-Asp-CMK induced cell death at micromolar concentrations in human leukaemia cells. Interestingly, low concentrations of Boc-Asp-CMK induced cell death with apoptotic hallmarks. Increasing concentrations of Boc-Asp-CMK led to necrotic cell death. The switch between apoptosis and necrosis seemed to depend upon the degree of inhibition of executioner caspases, including caspase-3/7 with Boc-Asp-CMK. Interestingly, caspase-3 processing was not inhibited even for the highest concentration of Boc-Asp-CMK used. We assume, that toxic properties of Boc-AspCMK can be attributed to the chloromethylketone residuum in its molecule, as its analogue Boc-AspFMK with fluoromethylketone residuum was more than 13 times less toxic. Our results further indicated that toxicity of Boc-Asp-CMK might arise from its interference with mitochondrial metabolism.
\end{abstract}

(c) 2008 Elsevier Ltd. All rights reserved.

\section{Introduction}

Caspases are a family of cysteine proteases that play a central role in apoptosis (Cohen, 1997). The involvement of caspases in apoptosis was first observed by the Horvitz's research group, who studied the programmed cell death in the nematode worm Caenorhabditis elegans (Ellis and Horvitz, 1986; Yuan et al., 1993). Since then, the conserved mechanism of apoptosis has been identified in a number of species, including humans.

The finding that caspases are indispensable for the apoptotic cell death programme has prompted the search for caspase inhibitors, which might offer a tool for modulation of this process. Synthetic peptide inhibitors that have been developed act by binding to the active site of caspases either in a reversible or irreversible manner. Inhibitor design includes a peptide recognition sequence attached to a functional group such as an aldehyde (CHO), chloromethylketone (CMK), or fluoromethylketone (FMK). Caspase inhibitors with CMK or FMK group are irreversible while those with $\mathrm{CHO}$ group are reversible. In general, protease inhibitors with FMK group are less reactive than those with CMK group and therefore

\footnotetext{
* Corresponding author. Tel.: +420 585632158; fax: +420 585632966.

E-mail address: mlejnek_petr@volny.cz (P. Mlejnek).

1 Both authors have equally contributed to this work.
}

are considered as more specific for the enzyme site being inhibited (Otto and Schirmeister, 1997).

Synthetic peptide inhibitors that are commercially available either exhibit some selectivity for the different caspases or act without apparent selectivity as broad-spectrum caspase inhibitors. First reports suggested that caspase inhibitors and particularly broad-spectrum caspase inhibitors could prevent cells from death. Further experiments, however, showed that this conclusion was oversimplified. At present time it is evident that caspase inhibitors can slow down cell death process and abrogate some apoptotic hallmarks but in fact they fail to prevent cells from death in most experimental systems (Green and Kroemer, 1998).

In this paper we demonstrate that the broad-spectrum caspase inhibitor Boc-Asp-CMK is toxic and induces cell death in micromolar concentrations. Its toxicity is probably due to CMK group in its molecule that interferes with mitochondrial functions.

\section{Materials and methods}

\subsection{Cell culture}

U937 cells were cultured in RPMI-1640 medium supplemented with $10 \%$ calf foetal serum and antibiotics in 5\% CO2 atmosphere at $37^{\circ} \mathrm{C}$. Cells were maintained at density from $1 \times 10^{5}$ to $6 \times 10^{5}$ cells per $\mathrm{ml}$. The cell density was determined using 
electronic particle counter ViCell (Beckman Coulter). Cells were obtained from ECACC.

\subsection{Chemicals and cell treatment}

Broad-spectrum caspase inhibitor, Boc-D-(OBzl)-CMK (Bachem, Bubendorf, Switzerland) and Boc-D-(OMe)-FMK (MP Biomedicals, Ohio, USA) were dissolved in DMSO. The final concentration of DMSO in culture medium was approximately $0.1 \%$. 3-(4,5-dimethylthiazol-2-yl)-2,5-diphenyltetrazolium bromide (MTT) was obtained from Duchefa (Haarlem, Netherlands). Propidium iodide and Hoechst 33342 were obtained from Fluka (Buchs, Switzerland).

\subsection{Determination of cell survival and proliferation}

The MTT assay was used for estimation of cell viability and growth as originally described by Mosmann (1983). Cells were incubated in the presence of $0.5 \mathrm{mg} \mathrm{MTT} / \mathrm{ml}$ (final concentration) for $1 \mathrm{~h}$ at $37^{\circ} \mathrm{C}$, then pelleted by centrifugation and extracted by isopropanol acidified with $0.01 \mathrm{M} \mathrm{HCl}$. Absorbance was read at $570 \mathrm{~nm}$ in extracts clarified by centrifugation. The amount of formazane produced is proportional to the number of live and metabolically active cells.

\subsection{Morphological analysis of apoptosis}

Cells were fixed and stained with Hoechst 33342 as described previously (Mlejnek and Kuglik, 2000). The nuclear morphology was examined using a fluorescence microscope.

\subsection{Measurement of caspase enzymatic activity in cell extracts}

Caspase-3/7 enzymatic activities were determined using fluorescent substrate, as described previously (Mlejnek, 2001).

\subsection{Immunoblot analysis (Western blot analysis)}

Pelleted cells were extracted by lysis buffer $(50 \mathrm{mM}$ Tris/HCl buffer pH 8.1 containing $1 \% \mathrm{NP}-40,150 \mathrm{mM} \mathrm{NaCl}, 50 \mathrm{mM} \mathrm{NaF}$, $5 \mathrm{mM}$ EDTA and $5 \mathrm{mM}$ sodium pyrophosphate, supplemented with protease (Roche) and phosphatase (Sigma) inhibitor cocktails). Cell extracts were mixed with $4 \times$ Laemmli buffer, and the samples were heated to $96{ }^{\circ} \mathrm{C}$ for $5 \mathrm{~min}$. Samples equivalent to $30 \mu \mathrm{g}$ protein were analysed by Western blot using a polyclonal anti-caspase-3 antibody (1:1000) recognizing both pro- and active forms, polyclonal anti-Akt antibody (1:1000; Cell Signalling Technology, Beverly, MA) or monoclonal anti- $\beta$-actin (1:2000; Sigma). The signal was detected using a horseradish peroxidase-conjugated secondary antibody (1:2000; Dako, Glostrup, Denmark). Products were visualized using an enhanced chemiluminiscence (ECL; Amersham, Little Chalfont, UK).

\subsection{Oxygen consumption}

Oxygen consumption (the respiratory activity) of intact cells was measured using a Clark-type oxygen electrode (Thermo Orion, Thermo Scientific, USA). A sample chamber with a stir magnet was filled with $1.9 \mathrm{ml}$ of fresh growth medium and allowed to equilibrate at $37^{\circ} \mathrm{C}$ for $5 \mathrm{~min}$. Measurement started by addition of $8.0 \times 10^{6}$ cells in volume of $0.1 \mathrm{ml}$ and oxygen consumption was monitored for $10 \mathrm{~min}$; subsequently, $20 \mu \mathrm{l}$ of KCN (final concentration, $1 \mathrm{mM}$ ) was added and oxygen consumption was monitored another $10 \mathrm{~min}$. The system was calibrated with oxygen-saturated water, which contains $217 \mathrm{nmol}$ of $\mathrm{O}_{2} / \mathrm{ml}$ at sea level, at $37^{\circ} \mathrm{C}$ for $1 \mathrm{~h}$. All oxygen consumption assays were repeated three times.

\subsection{Assessment of mitochondrial transmembrane potentials}

Cells were incubated for $15 \mathrm{~min}$ in $50 \mathrm{nmol}$ TMRE (tetramethylrhodamine ethyl ester perchlorate) at $37^{\circ} \mathrm{C}$ in growth medium. Stained cells were immediately analysed on a Cytomics FC 500 System (Beckman Coulter, Fullerton, CA, USA) with argon laser excitation at $488 \mathrm{~nm}$ and emission at $575 \mathrm{~nm}$. At least 10,000 cells in each sample were analysed. The control experiment was performed in untreated cells and in cells treated with $50 \mu \mathrm{mol}$ carbamoyl cyanide $m$-chlorophenylhydrazone ( $m \mathrm{ClCCP}$, an uncoupling agent that abolishes $\Delta \psi \mathrm{m}$ ) for $20 \mathrm{~min}$ at $37^{\circ} \mathrm{C}$.

\section{Results}

U937 cells responded to the treatment with Boc-D-CMK by a concentration dependent decrease in cell proliferation, which could be demonstrated by standard MTT assay (Fig. 1, Table 1). In contrast, its fluoromethylketone analogue, Boc-D-FMK exhibited only weak effect on cell proliferation (Fig. 1, Table 1). More detailed analysis revealed that Boc-D-CMK down-regulated Akt expression, that reflected not only decreased proliferation potential but also higher susceptibility of treated cells to death (Fig. 2). Indeed, we found that Boc-D-CMK induced cell death in U937cells. While concentrations up to $10 \mu \mathrm{M}$ of Boc-D-CMK induced apoptosis, higher concentrations induced necrotic-like cell death as judged from cell nuclei morphology (Fig. 3). These results indicated that the decrease in cell proliferation induced by Boc-D-CMK was mainly due to loss of cell viability (Fig. 1 and Fig. 3). On the other hand, the decrease in cell proliferation induced by Boc-D-FMK (Fig. 1) could be attributed only partly to the loss of cell viability (not shown). To confirm that cell death induced by low concentrations of Boc-D-CMK was apoptotic, we measured enzymatic activity of caspase-3/7. Our results clearly indicated that Boc-D-CMK could activate caspase-3/7 at low concentrations (Fig. 4). Western blot analysis confirmed that Boc-D-CMK induced caspase-3 activation (Fig. 5). Surprisingly, caspase-3 was activated even at concentrations of Boc-D-CMK that almost fully inhibited caspase- 3 activity (Figs. 4 and 5).

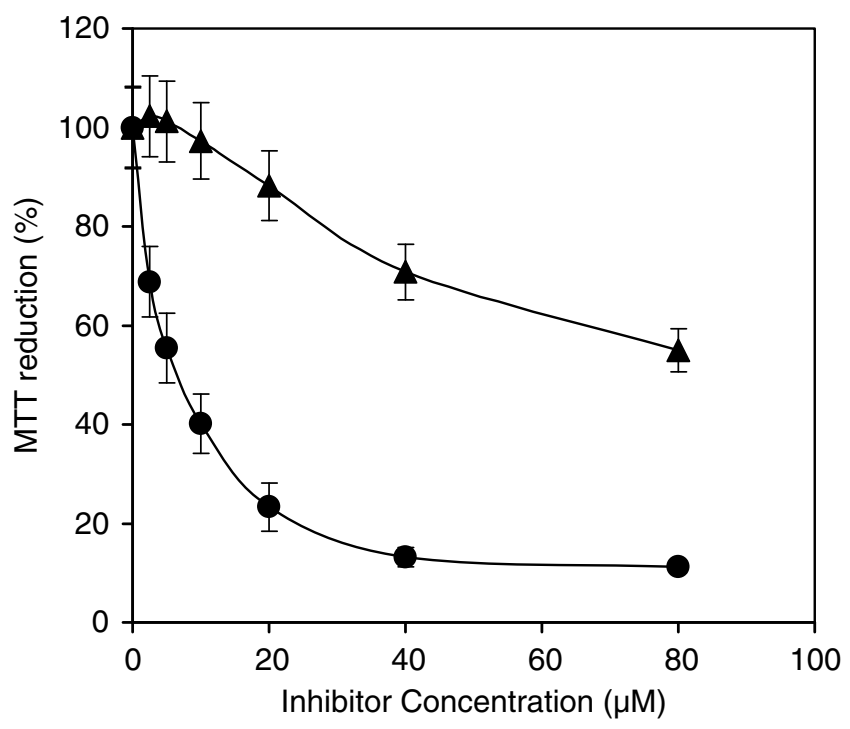

Fig. 1. Effect of Boc-D-CMK and Boc-D-FMK on proliferation of U937 cells. Cells were treated with Boc-D-CMK (circles) or Boc-D-FMK (triangles), as indicated. After $24 \mathrm{~h}$ incubation cells were subjected to the MTT assay. Untreated cells were taken as a control. The experimental points represent mean values from three replicate experiments with standard deviations. 
Table 1

Effect of Boc-D-CMK and Boc-D-FMK on proliferation and survival of U937 cells

\begin{tabular}{lc}
\hline Inhibitor & $\mathrm{IC}_{50}(\mu \mathrm{M})$ \\
\hline Boc-D-CMK & 6.8 \\
Boc-D-FMK & 91.1
\end{tabular}
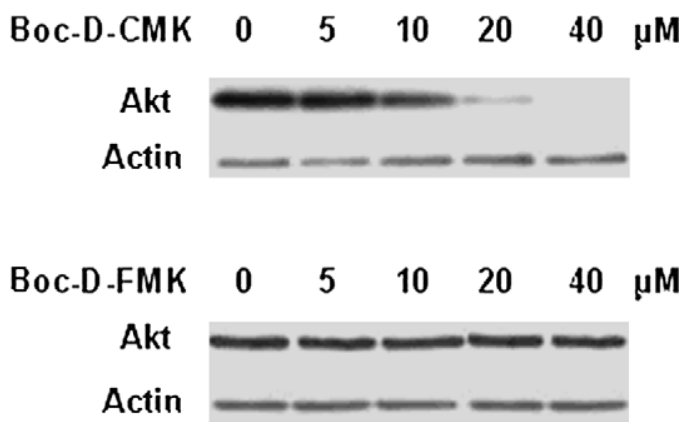

Fig. 2. Effect of Boc-D-CMK and Boc-D-FMK on Akt expression in U937 cells. Cells were treated with Boc-D-CMK or Boc-D-FMK, as indicated. After $24 \mathrm{~h}$ incubation cells were lysed and Akt expression was determined using Western blot analysis, see Section 2. Untreated cells were taken as a control. The pictures represent typical results from three replicate experiments.

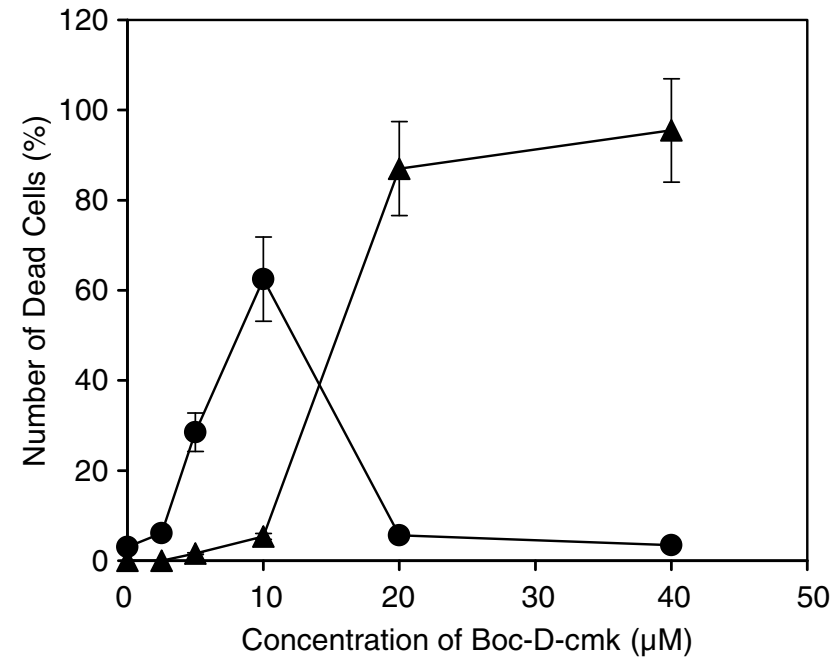

Fig. 3. Effect of Boc-D-CMK on nuclear morphology in U937 cells. Cells were treated with Boc-D-CMK for $24 \mathrm{~h}$, stained with Hoechst, and nuclear morphology was observed using fluorescence microscopy, see Section 2. Apoptotic nuclei (circles), necrotic nuclei (triangles). Untreated cells were taken as a control. At least 300 cells were counted in one sample. The experimental points represent mean values from three replicate experiments with standard deviations.

We further tried to identify cellular target of Boc-D-CMK, which could be responsible for the decrease of cell proliferation and cell death. We found that Boc-D-CMK inhibited cell respiration and this effect was found as early as $2-3 \mathrm{~h}$ after the treatment (Fig. 6). This event seemed to be the earliest adverse effect of Boc-D-CMK. Another event that indicated mitochondrial failure was the collapse of mitochondrial transmembrane potential $\Delta \Psi$, which was measurable several hours later (Fig. 7).

\section{Discussion}

The finding that a broad-spectrum caspase inhibitor can induce apoptosis sounds rather contradictory. However, detailed analysis

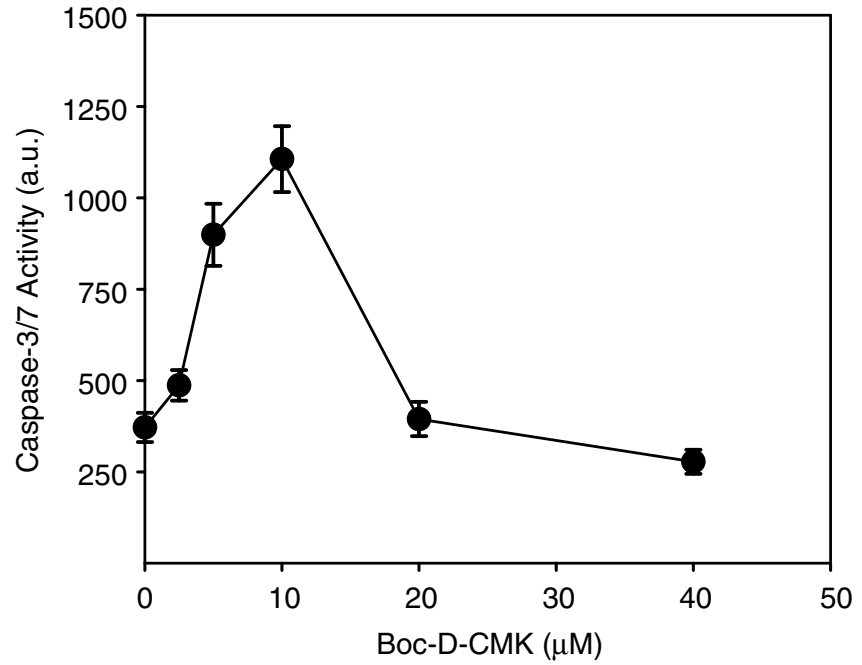

Fig. 4. Effect of Boc-D-CMK on caspase-3 activation in U937 cells. Cells were treated with Boc-D-CMK, as indicated. Caspase-3/7 (DEVDase) activity was determined in cell lysates after $18 \mathrm{~h}$ incubation using Ac-DEVD-AMC as substrate. Untreated cells were taken as a control. The experimental points represent mean values from three replicate experiments with standard deviations.

\section{$\begin{array}{llllll}0 & 5 & 10 & 20 & 40 & \mu M\end{array}$}

\section{Caspase-3}

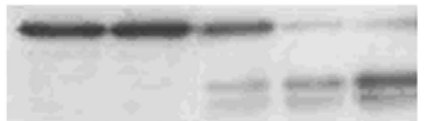

Actin

Fig. 5. Effect of Boc-D-CMK on caspase-3 processing in U937 cells. Cells were treated with Boc-D-CMK, as indicated. Caspase- 3 processing was determined after $18 \mathrm{~h}$ incubation in cell lysates using western blotting. Untreated cells were taken as a control. The picture represents typical results.

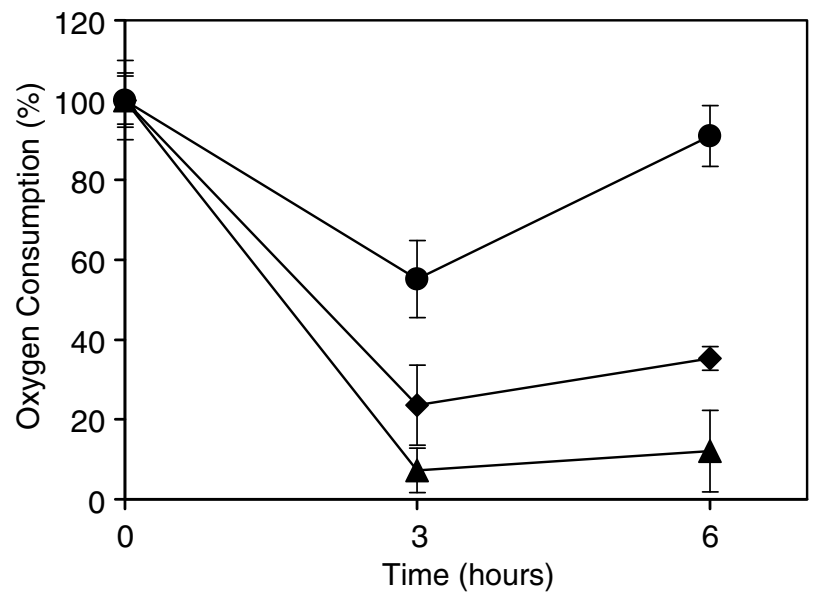

Fig. 6. Effect of Boc-D-CMK on respiration in U937 cells. Cells were treated with $5 \mu \mathrm{M}$ (circles), $10 \mu \mathrm{M}$ (squares), or $20 \mu \mathrm{M}$ (triangles) Boc-D-CMK. After indicated period oxygen consumption was determined using a Clark electrode (see Section 2). Untreated cells were taken as a control. The experimental points represent mean values from three replicate experiments with standard deviations.

of both our experimental data presented in this paper and data from literature offers consistent explanation for this finding. Thus, Boc-Asp-CMK is relatively weak inhibitor of caspase-3 and 


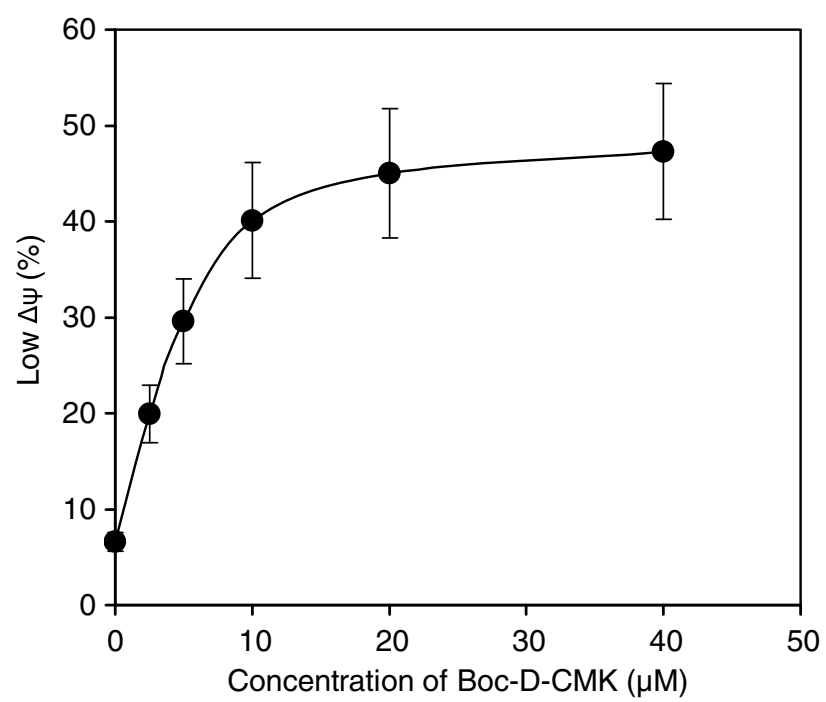

Fig. 7. Effect of Boc-D-CMK on mitochondrial transmembrane potential $\Delta \Psi$ in U937 cells. Cells were treated with Boc-D-CMK, as indicated. $\Delta \Psi$ was determined $6 \mathrm{~h}$ after the cell treatment as described in Section 2. Percentage of cells with low $\Delta \Psi$ (dead cells) is plotted against concentration of Boc-D-CMK. Untreated cells were taken as a control. The experimental points represent mean values from three replicate experiments with standard deviations.

estimated $\mathrm{IC}_{50}$ value was $6 \mu \mathrm{M}$ (Frydrych and Mlejnek, 2008). In addition, Boc-Asp-(OBzl)-CMK in contrast to its analogue BocAsp-(OMe)-FMK exhibited toxic effects at concentrations around the same value (Figs. 1 and 3; Table 1). These findings clearly indicated that Boc-Asp-(OBzl)-CMK could trigger apoptotic programme in treated cells. Indeed, we observed that concentrations up to $10 \mu \mathrm{M}$ could induce apoptosis with morphological (Fig. 3) and biochemical (Figs. 4 and 5) hallmarks. Effects of Boc-Asp-CMK can be compared to that found for TPCK ( $N$-tosyl-L-phenylalaninyl-chloromethylketone), which was reported to induce apoptosis (Wu et al., 1996; Drexler, 1997; Mlejnek, 2005) or at least enhance apoptosis induced by other cytotoxic agents (King et al., 2004; Okada et al., 2004). Moreover, TPCK similarly to Boc-Asp-CMK can act as nonspecific caspase inhibitor (Frydrych and Mlejnek, 2008).

We assume that the difference between toxic properties of BocAsp-(OBzl)-CMK and Boc-Asp-(OMe)-FMK can be attributed to the chloromethylketone functional group as it makes protease inhibitor less selective and more reactive than those with fluoromethylketone functional group (Otto and Schirmeister, 1997). However, there is one more difference between Boc-Asp-(OBzl)-CMK and Boc-Asp-(OMe)-FMK. While Boc-Asp-(OBzl)-CMK is benzylester, the Boc-Asp-(OMe)-FMK is methyl ester. This rise the possibility that higher toxicity of Boc-Asp-(OBzl)-CMK can be attributed to the benzyl alcohol which is released by esterases upon cell entry. This seems to be unlikely owing to the fact that benzyl alcohol does not exert adverse effects on U937 cells at relevant concentrations (unpublished results).

Boc-Asp-(OBzl)-CMK at concentrations above $10 \mu \mathrm{M}$ induced necrotic-like cell death, at least according to morphological changes (Fig. 3). This observation is not surprising regarding the fact that the z-VAD-FMK, efficient broad-spectrum caspase inhibitor blocks apoptotic cell death and sensitizes cells to necrotic cell death or alternatively it may induce autophagic cell death (Kitanaka and Kuchino, 1999; Vandenabeele et al., 2006). The switch from apoptosis to necrosis occurred at $15 \mu \mathrm{M}$ Boc-Asp-CMK i.e., before the enzymatic activity of caspase- $3 / 7$ was fully abrogated (not shown). However, $20 \mu \mathrm{M}$ Boc-Asp-CMK fully inhibited caspase-3/7 activity and $95 \%$ of dying cells acquired necrotic-like morphology (compare Figs. 3 and 4). Based on these results we can speculate that there might be an additional mechanism that diminished apoptosis and enhanced necrosis.

We further observed that Boc-Asp-CMK severely inhibited cell respiration and this event could be measured as early as $2 \mathrm{~h}$ after its addition to growth medium (not shown). Interestingly, concentrations up to $10 \mu \mathrm{M}$ of Boc-Asp-CMK caused reversible inhibition (Fig. 6). Higher concentrations caused irreversible inhibition (Fig. 6). The fast decrease of cell respiration was followed by fall of mitochondrial transmembrane potential $\Delta \Psi$ (Fig. 7). Although we have no direct evidence that Boc-Asp-CMK caused a severe depletion of ATP pool we can speculate that rapid and sustain inhibition of cell respiration might disrupt energetic metabolism of cells that contributes to necrosis.

Surprisingly, even highest concentration of Boc-Asp-CMK did not inhibit caspase-3 processing (Fig. 5). This is important finding since it was reported that broad-spectrum caspase inhibitor, $z-$ VAD-FMK, abrogated apoptosis by inhibiting of caspase- 3 processing (Cohen, 1997; MacFarlane et al., 1997). However, our results clearly indicated that Boc-Asp-CMK inhibited caspase-3 activity by direct inhibition rather than by inhibition of its processing (compare Figs. 4 and 5). Boc-Asp-CMK is relatively weak broadspectrum inhibitor and its effects mimic those found for TPCK (Frydrych and Mlejnek, 2008).

\section{Acknowledgements}

This work was supported by Grant \#MSM 6198959216 (Ministry of Education, Youth and Sports). This paper was partly sponsored by the ENTER research project which is co-financed by E.U.-European Social Fund and the Greek Ministry of Development-GSRT.

\section{References}

Cohen, G.M., 1997. Caspases: the executioners of apoptosis. The Biochemical Journal $326,1-16$

Drexler, H.C., 1997. Activation of the cell death program by inhibition of proteasome function. Proceedings of the National Academy of Sciences of the United States of America 94, 855-860.

Ellis, H.M., Horvitz, H.R., 1986. Genetic control of programmed cell death in the nematode C. elegans. Cell 44, 817-829.

Frydrych, I., Mlejnek, P., 2008. Serine protease inhibitors $N$-alpha-tosyl-l-lysinylchloromethylketone (TLCK) and $N$-tosyl-l-phenylalaninyl-chloromethylketone (TPCK) are potent inhibitors of activated caspase proteases. Journal of Cellular Biochemistry 103, 1646-1656.

Green, D., Kroemer, G., 1998. The central executioners of apoptosis: caspases or mitochondria. Trends in Cell Biology 8, 267-271.

King, M.A., Halicka, H.D., Darzynkiewicz, Z., 2004. Pro- and anti-apoptotic effects of an inhibitor of chymotrypsin-like serine proteases. Cell Cycle 3, 1566-1571.

Kitanaka, C., Kuchino, Y., 1999. Caspase-independent programmed cell death with necrotic morphology. Cell Death and Differentiation 6, 508-515.

MacFarlane, M., Cain, K., Sun, X.M., Alnemri, E.S., Cohen, G.M., 1997. Processing/ activation of at least four interleukin-1beta converting enzyme-like proteases occurs during the execution phase of apoptosis in human monocytic tumor cells. The Journal of Cell Biology 137, 469-479.

Mlejnek, P., Kuglik, P., 2000. Induction of apoptosis in HL-60 cells by N(6)benzyladenosine. Journal of Cellular Biochemistry 77, 6-17.

Mlejnek, P., 2001. Caspase inhibition and N(6)-benzyladenosine-induced apoptosis in HL-60 cells. Journal of Cellular Biochemistry 83, 678-689.

Mlejnek, P., 2005. Can application of serine protease inhibitors TPCK and TLCK provide evidence for possible involvement of serine protease Omi/HtrA2 in imatinib mesylate-induced cell death of BCR-ABL-positive human leukemia cells? Leukemia 19, 1085-1087.

Mosmann, T., 1983. Rapid colorimetric assay for cellular growth and survival: application to proliferation and cytotoxicity assays. Journal of Immunological Methods 65, 55-63.

Okada, M., Adachi, S., Imai, T., Watanabe, K., Toyokuni, S.Y., Ueno, M., Zervos, A.S., Kroemer, G., Nakahata, T., 2004. A novel mechanism for imatinib mesylateinduced cell death of BCR-ABL-positive human leukemic cells: caspaseindependent, necrosis-like programmed cell death mediated by serine protease activity. Blood 103, 2299-2307.

Otto, H.H., Schirmeister, T., 1997. Cysteine proteases and their inhibitors. Chemical Reviews 97, 133-172.

Vandenabeele, P., Vanden Berghe, T., Festjens, N., 2006. Caspase inhibitors promote alternative cell death pathways. Science's STKE: Signal Transduction Knowledge Environment 358, 44. 
Wu, M., Lee, H., Bellas, R.E., Schauer, S.L., Arsura, M., Katz, D., FitzGerald, M.J., Rothstein, T.L., Sherr, D.H., Sonenshein, G.E., 1996. Inhibition of NF-kappaB/Rel induces apoptosis of murine B cells. The EMBO Journal 15, 4682-4690.
Yuan, J., Shaham, S., Ledoux, S., Ellis, H.M., Horvitz, H.R., 1993. The C. elegans cell death gene ced-3 encodes a protein similar to mammalian interleukin-1 betaconverting enzyme. Cell 75, 641-652. 